\title{
A Computationally Intelligent Power Transmission Expansion Strategy in a Deregulated Energy System
}

\author{
Christopher O. Ahiakwo, Sunny Orike, and Ahuruezemma O. Obioma
}

\begin{abstract}
This paper aims to simulate a computationally intelligent electrical power transmission expansion system and study the factors affecting power transmission expansion in a deregulated energy system to improve on the current economic conditions. The main problem facing most power system transmission is the failure to actually forecast the load expansion accurately this leads to failure in the transmission expansion design. a hybrid algorithm for the ac/dc transmission expansion planning (HTEP) and multi algebraic formulation of the stochastic TEP model in a multi-stage planning framework will be used to analyze the transmission expansion system, optimization problem will considers a weighted sum of multiple objectives including cost of operation and maintenance, emission, load shedding and line investments, simulation method would consider random outages of generating units and ac/dc transmission lines as well as load forecast .The independent system operator would utilize the proposed method to select the optimal set of ac/dc transmission lines for satisfying TEP criteria. The proposed set of dc transmission system may use either current source converters or voltage source converters. The proposed algorithms are simulated on IEEE 24-bus reliability test system (RTS) and Gerner's 6 bus system to compare optimal plans between the original and equivalent system. Further assumptions and adjustments are searched and tested to get more accurate optimal plans. results obtained showed that the hybrid model was capable of handling future generation and load patterns in deregulated, unbundled, and competitive electricity system. the results of the study showed the hybrid model was tested in the Gerner's 6 bus system and the expansion model after a load forecast. On the IEEE 24-bus system showed that the hybrid expansion model was able to take care of the load forecast for future expansion
\end{abstract}

Index Terms-Deregulation; Electrical Power System; Expansion Strategies; Transmission.

\section{INTRODUCTION}

Electrical energy is indisputably the most important element that is paramount to socio-economic growth and technological advancement of every nation in the world [1]. Nigeria is not an exception to the above-mentioned statement; unfortunately, electric energy demand has far exceeded the available supply in Nigeria. More so, even the available supply of electric energy has been epileptic at best. The major reason behind this dis-heartening condition of our nation

Published on May 14, 2018

C. O. Ahiakwo is currently the Dean, Faculty of Engineering, Rivers State University, Port Harcourt, Nigeria (e-mail: chrisahias@ust.edu.ng).

$\mathrm{S}$. Orike is a Lecturer in the Department of Electrical Engineering, Rivers State University, Port Harcourt, Nigeria. (e-mail: orike.sunny@ust.edu.ng).

A. O. Obioma is a Master of Technology Student in the Department of Electrical Engineering, Rivers State University, Port Harcourt, Nigeria (e-mail: obioma.a.obioma@gmail.com).
Nigeria, is poor transmission of electric energy due to lack of state-of-the-art infrastructure, inherent weakness in the existing electric energy transportation system and of course the inadequate investment in the generation sector in the generation sector in the power system [2]. This implies that, the nearly 200 million people of the society will find electricity availability an ardors task, translating into an energy deficient society with $121 \mathrm{KWh}$ per capita. This is 50 times less than average country in Europe with $10 \%$ of Nigeria's population. The resultant effect of the issues on the electricity-producing sector of the country is evident in the very poor human development index despite the plenty of natural resources in the nation.

This is very much true as it is generally accepted that, there is a correlation between the socio-economic development of a nation and the electricity of availability. In other words, the socio-economic growth of a nation depends on the available supply of electric energy [3]. Apparently, this abysmal situation has necessitated the need for the reformation of the power sector and restructuring the entire power system, which implies that, planning of the power system with its associated challenges must be decentralized. This coupled with operational difficulties; long term transmission planning is now a serious issue [4]. It was in the cause of de-regulation that the existing electric power policy plan mandated the Energy Commission of Nigeria (ECN) to ensure long-term energy requirement strategies, which will lead the nation to industrialization. Given the vast amount of mineral deposits in the country (as shown in Table 1), ECN made three energy requirements forecast which if explored could achieve the objective of efficient and effective utilization of the mineral deposits in a flawless electricity generation mix [3]. However, for these 3-energy demand scenarios that were forecasted, there was or never has been a long-term transmission plan that will serve as a support to the evolving power sector [5]-[7] This no doubt has given rise to the insufficient supply of electric energy, which in turn is triggered by the radial nature of the concentration of generation in some region [8].

Therefore, it becomes clear that this nation needs a fresh guide in the transmission sector to lead us to the promise land of sufficient energy supply. The resultant benefit of revamping the transmission system would range from providing support to the strict adherence to the energy demand plans to giving incentives to the various investors in the energy sector following the existing restructuring process.

TABLE I: ENERGY SOURCES IN NIGERIA

\begin{tabular}{lc}
\hline $\begin{array}{l}\text { ENERGY RESOURCES IN NIGERIA } \\
\text { nergy type }\end{array}$ & Reserve estimates \\
\hline Crude oil & 36 billion barrels \\
\hline
\end{tabular}




\begin{tabular}{ll}
\hline \hline Natural gas & 185 trillion cubic feet \\
Coal & 2.75 billion metric tons \\
Hydro & $14.7 .0 \mathrm{MW}$ \\
Solar Radiation & $3.5-7.0 \mathrm{KWh} / \mathrm{m}^{2} /$ day \\
Wind energy & $2.0-4.0$ \\
Biomass & 144 million tons/year \\
Waves and tidal energy & $150,000 \mathrm{TJ} / 16.6 \times 10^{6}$ ton $/ y r$ \\
\hline \hline
\end{tabular}

\section{BACKGROUND STUDY}

\section{A. Problem Statement}

According to [4], "transmission expansion problem is a wicked problem". It is a teething problem where technological issues are mixed with issues that border on policies of the various stakeholders and investors of the power system as well as the uncertainties that are involved [9]. There is high level of uncertainties at both the generation side and the demand side of the power system. Thus, it becomes an ardors task for the planner to put all these uncertainties into consideration to plan and design a network that can capability accommodate the said uncertainties.

The planner must take in account the performance of all generators in the system as well as the uncertainties in future demand. All these are uncertainties because future demand growth and consumption pattern are not very clear to the planner or the decision makers [11]. More so, acquiring right of way for overhead line installation is quite expensive and time consuming as the planner will have to negotiate with all landowners in the corridors of transmission [12]. Due to these challenges mentioned above, transmission expansion projects usually lay behind the scheduled time by which time generators are ready to connect. Thus, the lack of transmission capacity forces the delay in generation connection or constraining them to be operated below their actual capabilities.

\section{B. Fundamentals of Transmission Planning}

The chief aim of every transmission network is to reliably efficiently and economically deliver electric energy to consumers from the generation sectors, network expansion planning on the other hand seeks to optimize investment cost as well as minimize operation cost investment cost is the total capital spent on installing new transmission elements along with reinforcement of the existing network, whereas the cost incurred in generating electric power by the various power plants distributed in various geographical is called operational cost zones [13]. It is quite interesting to note that, the investment cost and operational cost have antithetical objectives. The higher the investment cost or customer's outage cost and vice versa. In fact, one can say that investment cost and operational cost approximately bear an inverse proportion relationship [14]-[16]. Fig. 1 shows the concept that a global optimal plan reconciles these contradictory objectives.



Fig. 1. The Investment Cost versus Operating Cost

In general, a transmission expansion plan should be able to address the following three questions [17]:

- Where are the transmission lines required?

- What are the capacities of the transmission lines?

- When the transmission lines should be commissioned.

The following two different methods can be employed to proffer solution to the above three questions [5].

- Static planning

- Dynamic planning.

Static planning deals with the questions of where and what while the second approach includes the question of when [6]. Dynamic planning is usually complex and very large as it includes all time constraint (restrictions) coupling transmission expansion projects over the years together [16] For energy security reasons, the transmission network should be robust against outages of transmission elements such as tripping of overhead lines and cables, etc. Thus, the continuity of supply to consumers must be preserved irrespective of incontinences affecting the network. Transmission networks is usually a ring system or mesh connection of overhead cables so that many credible outages need to be taken into consideration, during planning.

\section{Dynamic and Static Transmission Planning}

Static planning views just a single horizon year in this approach, planners are not concerned whether a transmission line proposed for the horizon is required to be in service in the years before the horizon year [6]. Usually, the planning horizon in static planning is five to seven years ahead of the time when the study is carried out [18].

More so, in static transmission planning, the equivalent annual cost of transmission investment and all other cost are determined for the planning horizon. The equivalent annual cost of investment of a network expansion project is dependent on the life-time of the assets (n), the total investment cost (p) and interest rate (r) which is mathematically expressed as [8]:

$E A C=P\left[\frac{r(1+r)^{n}}{(1+r)^{n}-1}\right]$

Where:

$\mathrm{EAC}=$ Equivalent annual cost of investment

$\mathrm{P}=$ Total investment

$\mathrm{r}=$ Interest rate

$\mathrm{n}=$ Asset's lifetime 
To plan for the most economic transmission expansion plan which will satisfy security criteria i.e. continuity of supply in times of in contingencies, the objective function for a static transmission planning study can be expressed as:

Minimize $\sum_{i=1}^{\overline{N L}} X_{i} E A C_{i}$

Where:

$\mathrm{EACi}=\quad$ Annual cost of transmission line

$\mathrm{X}=$ Binary variable which shows if transmission line $\mathrm{i}$

is required and $\bar{N}_{L}$ is the number of candidate lines.

However, in dynamic planning, the planning is carried out at different intervals of several years [19]-[20]. The transmission scheme is optimized at each interval of the given period of years over which the planning is to be carried out. During the optimization period, variations in load growth, interest rate variations and decommissioning assets are seriously put consideration. One major difference between dynamic and static planning is that dynamic planning specifies that in which year of planning interval a transmission line should be commissioned. The objective function considering time of installation of the transmission lines is given by (3):

Minimize $\sum_{j=1}^{N D} \sum_{i=1}^{N L} X_{i}^{j} . E A C_{i}^{j}$

Where: ND is the number of years.

\section{Transmission Network Models}

The electric power transmission network is analogous in some respect to road transportation system this analogy is borne out of the fact that, both are means through which commodities are conveyed from suppliers to consumers [21]. However, the distinguishing difference between the two types of transport system is that, transmission networks are constrained to comply with some physical laws which is not the case when considering road transportation system. The physical laws under whose influence the network is subjected express the relationships among variables in the power system such as voltages, voltage angle, active and reactive powers. Transmission planning in power system studies can be modeled with one of the following models:

(i) Alternating current (AC) model

(ii) Direct current (DC) model

(iii) Transportation model

In AC model, there exists a non-linear relationship among variables in the system [22] The active power $\left(\mathrm{P}_{\mathrm{K}}\right)$ and reactive power $\left(\mathrm{Q}_{\mathrm{K}}\right)$ flowing in a transmission line $\mathrm{k}$ between bus $\mathrm{i}$ and $\mathrm{j}$ can be given by:

$$
\begin{aligned}
& P_{K}=V_{i} V_{j}\left[G_{i j} \operatorname{Cos}\left(\theta_{i}-\theta_{j}\right)+B_{i j} \operatorname{Sin}\left(\theta_{i}-\theta_{j}\right)\right]-G_{i j} V_{i}^{2} \\
& Q_{K}=V_{i} V_{j}\left[G_{i j} \operatorname{Sin}\left(\theta_{i}-\theta_{j}\right)-B_{i j} \operatorname{Cos}\left(\theta_{i}-\theta_{j}\right)\right]+B_{i j} V_{i}^{2}
\end{aligned}
$$

Where:

$\mathrm{V}_{\mathrm{j}}=$ Voltage magnitude at bus $\mathrm{j}, \theta_{\mathrm{j}}=$ Voltage angle at bus $\mathrm{j}$
Gij $=$ Real part of $i^{\text {th }}, \mathrm{J}^{\text {th }}$ element of the modal admittance matrix. Now if $r_{i j}$ and $x_{i j}$ are the resistance and reactance of the transmission line connecting bus $i$ and $j$ respectively then $\mathrm{G}_{\mathrm{ij}}$ and $\mathrm{B}_{\mathrm{ij}}$ can be mathematically expressed as:

$$
G_{i j}+J B_{i j}=\frac{r_{i j}}{r_{i j}^{2}+X_{i j}^{2}}-j \frac{X_{i j}}{r_{i j}^{2}+X_{i j}^{2}}
$$

Equations (4) and (5) are considered as non-linear constraints to a transmission planning problem which considers the alternating current model for the network, thus making the planning problem a non-linear optimization problem. One of the major issues confronting the network planner is the non-linearity of power system variables [23]. However, some studies have assumed the A.C model for network planning howbeit after some linearization was applied to the final model.

The complexities associated with the A.C model such as excessive time consumption and computationally expensive optimization have paved way for the deployment of the D.C model. The D.C model can be seen as the linearized version of A.C model, the D.C model, apart from its simplicity also expresses the fundamental relationships of parameters in the power system. In fact, simplicity is the main reason behind the wide acceptance of the D.C model. In the deployment of the D.C model, the following three main assumptions were made [24]:

- The magnitude of the voltage at all buses is equal to I.P.U., i.e. $\mathrm{V}_{\mathrm{i}}=1$

- Reactance is much greater than resistance in the transmission network.

- The difference between voltage angles of two endings of a transmission line is quite small or negligible i.e. $\operatorname{Cos}\left(\theta_{\mathrm{i}}-\theta_{\mathrm{j}}\right)=1$, $\sin \left(\theta_{\mathrm{i}}-\theta_{\mathrm{j}}\right)=\theta_{\mathrm{i}}-\theta_{\mathrm{j}}$. using these three assumptions, the A.C model can be successfully linearized, consequently, Equations (4) and (5) can be transformed into:

$P_{K}=\frac{1}{X_{i j}}\left(\theta_{i}-\theta_{j}\right)$

Another indispensable constraint in the D.C model is the balance of power at each bus. If for instance we are considering bus d, then the Kirchhoff's current law (KCL) is given by (8).

$$
\sum_{\nabla i E N_{g d}} G_{i}+\sum_{\nabla K E N_{L d}} P_{K}-L_{d}=0
$$

Where:

$\mathrm{N}_{\mathrm{gd}}$ and $\mathrm{N}_{\mathrm{Ld}}=$ Set of generations and transmission lines connected to bus d, respectively;

$\mathrm{G}_{\mathrm{i}}=$ Power generated by generator in (MW);

$\mathrm{L}_{\mathrm{d}}=$ Load at bus d (MW) from (7) and (8).

It has become obvious that a transmission planning which deploys the D.C model does not consider reactive power and reactive voltage magnitude. For long-term planning as in most research works, the D.C model is a very good viable 
option, even though the final proposed network is checked using A.C model in order to ensure the non-existence of violations in the future network [14] The final network topology should meet all operational criteria. For a given demand and generation scheme in conjunction with possible candidate lines in a horizon year, the planning is done using D.C model and the possible network violations are evaluated using A.C model if any violation is encountered, reactive power resources or some cases some transmission lines may be suggested so that plan satisfy all security criteria.

Transportation model is the least accurate model of all the three models of transmission network. In most case, the model is used to make a rough estimate of power flows between regions. Transportation model is also used to determine transmission corridors considered transmission expansion candidates in the transmission planning studies using D.C or A.C models. In the transmission planning studies using D.C or A.C models.

\section{E. Decomposition Techniques}

Largely, transmission network planning is a large-scale optimization problem as it is subjected to many constraints, modeling the security criterion along with performance requirement of the network at various load levels [20]. Furthermore, the magnitude of the transmission problem exponentially increases when network parameters associated with uncertainties are involved. An ideal approach would be to integrate the optimization problem, which includes all constructed network, and contingent networks so that the optimal transmission capacities for both cases are simultaneously calculated [21]. However, due to the complex nature of this approach, even optimization software is usually unable to solve such a large-scale problem [6]. The alternative approach, which largely proffers solution to these types of problem, is the use of decomposition techniques such as Bender's decomposition, Dantzig-Wolfe relaxation [15]. Decomposition techniques briefly breaks or split the whole problem into sub-problems which need little or less computational effort. Among all the decomposition techniques, Bender's decomposition has received great attention and has been warmly embraced by power system planners.

Bender in 1962 became the originator or proposed this type of decomposition technique, but it was further developed by Geoffrion in 1972. Since then, the technique has been widely used to tackle large-scale centralized decision-making problems [22]. Bender's decomposition technique divides a centralized problem into a master problem and several sub-problems. Solution to some decision variables is proffered by the master problem while the sub-problems propose solutions for other decision variables and associated constraints. The master problem and the sub-problems interact with other through bender's cuts. Bender's cut is a form of optimality cut or feasibility cut [10]. As time progresses, there is an increasing wide application of bender's decomposition techniques more especially in a de-regulated power system.

In a de-regulated system, power system planning takes a decentralized fashion in which transmission companies are responsible for transmission expansion whereas generation companies (GENCOs) are concerned with commissioning and de-commissioning of generating units [22]. In the steady state power system analysis, the lumped parameter $\pi$ equivalent model as shown in Fig. 2 is often used to model an AC Transmission line.

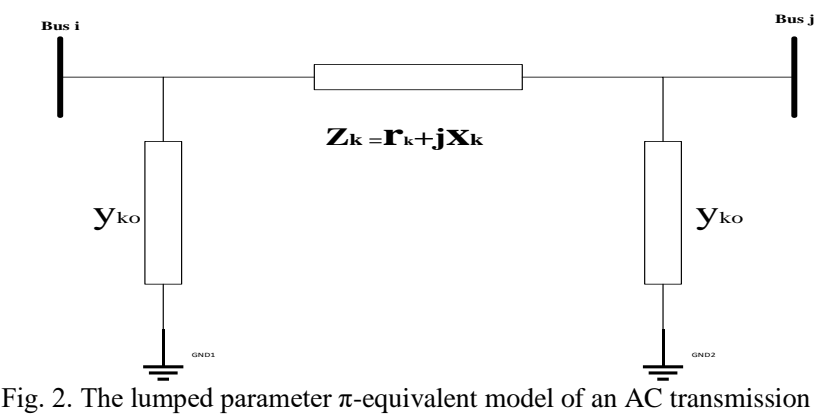
line

$Z_{K}$ is the series impedance of the line and can be written as:

$Z_{K}=r_{k}+j X_{k}$

where $r_{k}$ and $X_{k}$ are referred to as the resistance and reactance of the line, respectively. When formulating the network equations, the series admittance is needed. The series admittance of the line is defined as the reciprocal of the series impedance and takes the following form:

$Y_{k}=\frac{r_{k}}{r_{k}^{2}+x_{k}^{2}}+\frac{-x_{k}}{r_{k}^{2}+x_{k}^{2}}$

$Y_{K}=Z_{K}^{-1}=g_{k}+j b_{k}$

Where $g_{k}$ and $b_{k}$ are referred to as the conductance and susceptance of the line, respectively. It should be noticed that in the power system, $g k$ is always positive while $b k$ is usually negative. In the $\pi$ equivalent model, the total line charging admittance is divided by half and connected at the two terminals of the line denoted by $y k 0$.

In the power system, the real part of $y k 0$ is usually zero $(g k 0=0)$ and only the shunt susceptance $(b k 0)$ is considered.

In $\mathrm{AC}$ power systems, the complex power flow in a line is denoted by:

$S_{k}=P_{k}+j Q_{k}$

Where $P_{k}$ and $Q_{k}$ are the active and reactive power flows respectively [6]. Separating the real and imaginary parts in (13) and defining $i$ and $j$ as the two terminal buses of the line, the active and reactive power flows from bus $i$ to $j$ is calculated by the following equations:

$$
\begin{aligned}
& P_{k}{ }^{(i j)}=V_{i}^{2} g_{k}-V_{i} V_{j}\left(g_{k} \cos \theta_{k}+b_{k} \sin \theta_{k}\right) \\
& Q_{k}{ }^{(i j)}=-V_{i}^{2}\left(b_{k}+b_{k o}\right)+V_{i} V_{j}
\end{aligned}
$$

Where $\theta k$ is the phase angle difference between bus $i$ and bus $j$, i.e., $(\theta i-\theta j)$. The active and reactive power flows in the same line but metered from the opposite direction can be obtained in a similar way: 
$P_{k}{ }^{(j i)}=V_{i}^{2} g_{k}-V_{i} V_{j}\left(g_{k} \cos \theta_{k}-b_{k} \sin \theta_{k}\right)$

$Q_{k}^{(j i)}=-V_{i}^{2}\left(b_{k}+b_{k o}\right)+V_{i} V_{j}\left(b_{k} \cos \theta_{k}+g_{k} \sin \theta_{k}\right)$

In power systems, the active power loss of a line is the active power consumed by the series resistance of the line. Using (15) and (16), the active power loss of the line is obtained as:

$P L_{k}=g_{k}\left(V_{i}^{2}+V_{i}-2 V_{i} V_{j} \cos \theta_{k}\right)$

Similarly,

$Q L_{k}=-b_{k o}\left(V_{i}^{2}+V_{j}^{2}\right)-b_{k}\left(V_{i}^{2}+V_{j}^{2}-2 V_{i} V_{j} \cos \theta_{k}\right)$

The definition of reactive power loss on a line can be tricky, because the reactive power is both consumed and generated along the line [4]. The first term in (18) is the reactive power generated by the charging (capacitive) susceptance in the $\pi$-equivalent model, while the second term represents the reactive power consumed by the line (inductive) reactance.

\section{MATERIALS AND METHOD}

A typical network structure consisting of 13 buses represents the transmission lines, called branches. There can be more than one branch between two buses. An arrow at a bus indicates that there is power demand. They are also called load buses. Load buses consist of both active power demand, $P_{d}$ and reactive power demand, $Q_{d}$. Buses to which generator are connected are called generator buses. A generator bus denoted as $\mathrm{G}$ consist of both active power output $P_{g}$ and reactive power output $Q_{g}$ whereas a generator denoted by $\mathrm{C}$ is called a synchronous condenser and has only reactive power output. Power transmitted from generator to load over a conducting line is denoted by $\mathrm{P}$ and mathematically defined as the product of voltage $\mathrm{V}$ and current I.

$\mathrm{P}=\mathrm{V} \times \mathrm{I}$

Hence, for a given power, the voltage $\mathrm{V}$ and current $\mathrm{I}$ can be varied to achieve this same result. Since the line through which the power is transported is not a perfect conductor, there exist power losses in the line. The power loss is expressed as

$$
P_{\text {Loss }}=I^{2} R=R \times\left(\frac{P}{V}\right)^{2}
$$

Where:

$$
\begin{aligned}
& \mathrm{R}=\text { Resistance, } \\
& \mathrm{I}=\text { Current } \\
& \mathrm{P}_{\text {Loss }}=\text { Line losses }
\end{aligned}
$$

To make the calculation in an electricity network with multiple voltage levels easier, the per-unit-system is normally used. Within a voltage is measured with regards to the nominal voltage referred to as the base voltage. The nominal voltage is defined as 1.0 per unit voltage. The equation below represents the conversion into per unit (P.U):

per unit $=\frac{\text { Current value }}{\text { Base value }}$

Each power grid in the figure below is rated in mega voltampere MVA. The base power $S_{\text {base }}$ is usually set to 100MVA. Thus the voltage base $\mathrm{V}_{\text {base }}$ and the current base $\mathrm{I}_{\text {base }}$ are used to calculate each other.

$$
\int_{\text {base }} 3 \phi=\sqrt{3 \times V_{\text {base }} \times I_{\text {base }}}
$$

Where the term $\sqrt{3}$ is used in 3 - phase system, and $\mathrm{V}_{\mathrm{L}-\mathrm{L}}$ means the line-to-line voltage.

$$
\begin{aligned}
& Z_{\text {base }}=\frac{V_{\text {base }^{2}}^{2}}{\int_{\text {base }_{3-Q}}}=\frac{V_{\text {base }_{L-L}}}{I_{\text {base }}} \\
& Z_{P . U}=\frac{Z_{\text {base }}}{Z_{\text {base }}}
\end{aligned}
$$

Where $Z_{P . U}$ is the impedance of the network in per unit, and $\mathrm{Z}$ is the current value of the impedance and $Z_{\text {base }}$ is the base impedance. Thus, it can be inferred that, using of high voltages for a given power result in the decrease of the current and consequently a reduction in line losses. The drawback is that high voltage transmission increases the cost of the transmission system.

\section{RESULTS AND DisCUSSION}

Analysing the various simulation results of the transmission expansion plan for different condition simulated in MATLAB for the IEEE 24 bus system and Garver's 6 Bus system under different conditions and a load forecast analysis for 15 years to compute the best method to properly optimize the transmission station for a deregulated power system [23].

TABLE II: SIMULATION RESULTS USING HTEP FOR AC AND DC MODEL

\begin{tabular}{lll}
\hline \hline & $\begin{array}{l}\text { Garver's System } \\
\text { (solution 1) }\end{array}$ & $\begin{array}{l}\text { Garver's System } \\
\text { (solution 2) }\end{array}$ \\
\hline Transmission lines & 250.000 & 250.000 \\
Power losses & 55.00 & 55.00 \\
Var sources & 20.750 & 17.48 \\
Total & 325.750 & 322.480 \\
\hline \hline
\end{tabular}

As indicated, with different topologies, transmission line costs are equal for both solutions, but solution 2 is preferred since it has a lower total investment cost. The results obtained through this example illustrate a significant realization of simultaneous transmission expansion and reactive power source allocation. Additionally, the final topology may have a reliable operation when tested with an AC power flow, so the solution may not require additional transmission line reinforcement. Such reinforcements, starting with the transmission line planning, are generally necessary when a DC model is used to handle the planning process. The solution for a DC model of this system is reported in where the investment cost is 200.000 with 
installation of the following lines: $n 26-=4 ; n 35-=1 ; n 4$ $6-=2$. This solution falls short when AC network is considered, however, the results obtain.

TABLE III: TEP RESULT FOR THE IEEE 24 BUS SYSTEM

\begin{tabular}{ll}
\hline \hline Lines to be built & $(3-5),(8-9),(9-10),(26-30)$ \\
Investment cost MN & 43 \\
Total operating cost MN & $1567.4(10$-year $)$ \\
Solution time & 4 \\
\hline \hline
\end{tabular}

As observed from Table 3, four new lines are needed for this two-stage security constrained planning problem, and all of them need to be built in Year 1 for economic purposes. During the ten-tear planning horizon, the total investment and the operating cost are about 1567 Million Naira. The computation time is about 4 seconds. Notice that the result obtained above only gives a high-level picture of how the system can be designed reliably and economically for the long run based on the best estimate at the present.

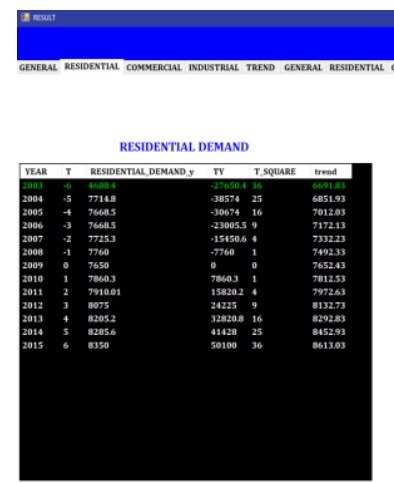

\section{RESULT}

Fig. 3. Graph of Nigeria actual residential load demand and trend values from $2003-2015$

Fig. 3 shows Nigeria actual residential load demand from 2003 to 2015 where the orange colour is the trend value and the blue is the actual residential demand. The result shows that there has been a sharp, increase in the electrical load demanded by residential houses during 2003 to 2004 and a constant steady increase can be seen from the trend analysis this shows that in the future that the load demanded for residential housing will continue to increase rapidly.

The power demanded for commercial use has not been stable for recent years as depicted in Fig. 4, but there has been a significant load increase from 2004 to 2005 the load demand increased with over a $1000 \mathrm{MW}$ this load demanded is constantly increasing for the last thirteen years and in likely to increase in the future, as more commercial business continues to spring out in the country.

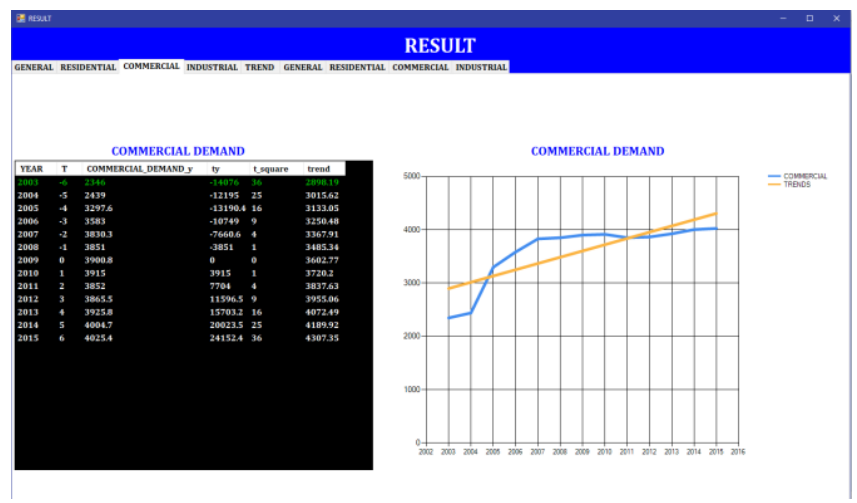

Fig. 4. Graph of Nigeria actual commercial load demand and trend values from $2003-2015$

The industrial load demand in Nigeria had a sharp increase from 2003 to 2004, as a result of the influx of many companies during this interval and it witnessed a sudden fall. Thereafter, it has been fluctuating due to fluctuations in production from the various industries as some industries also shut down some of their plants while other new plants are built this account for the fluctuations in the load demanded. The industrial load demanded was generally higher as compared to that of residential and domestic, the industrial machines draws more power than residential equipment, also it can be seen from Fig. 5 that the industrial demand has a constant increasing slope, this show that it would increase in future times.

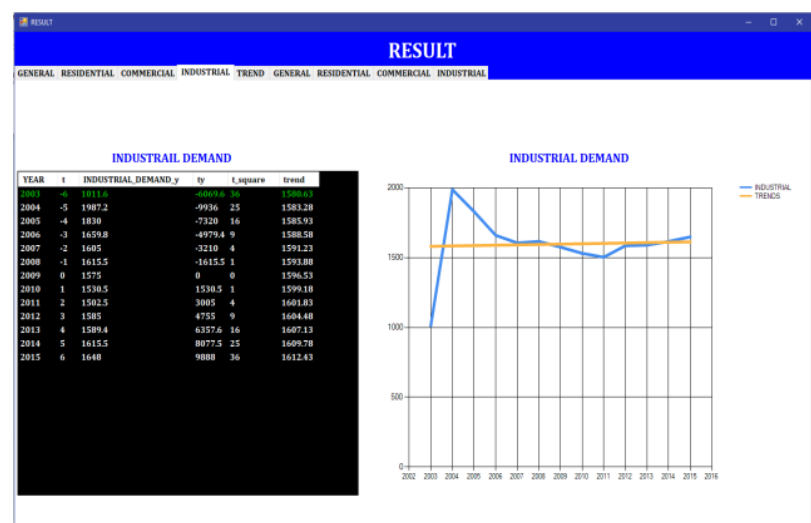

Fig. 5. Graph of Nigeria actual industrial load demand and trend values from $2003-2015$

A comparative study of the various trends shows that the residential load demand is higher than the commercial and industrial (see Fig. 6 and 7). This is due to the fact that more commercial and residential facilities that use power are being constructed than the rate at which industries are established in the country, so more focus should be given to the residential load demand as population expands daily.

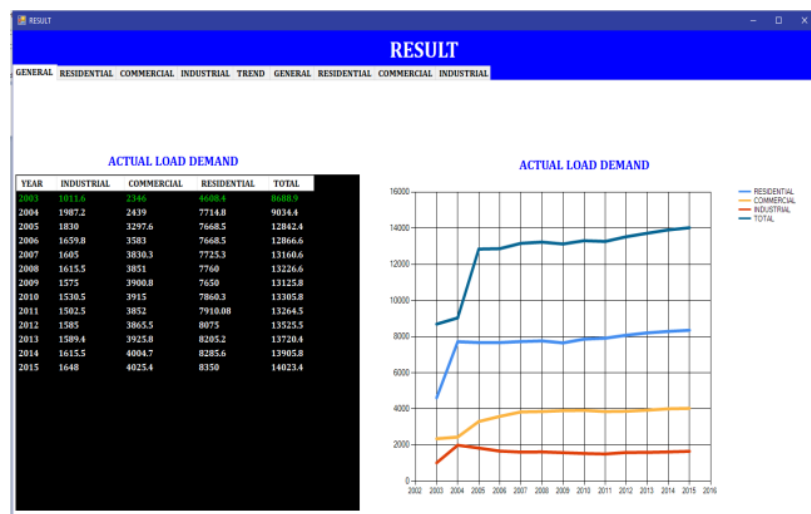

Fig. 6. Graph of Nigeria actual load demand and trend values from $2003-2015$ 


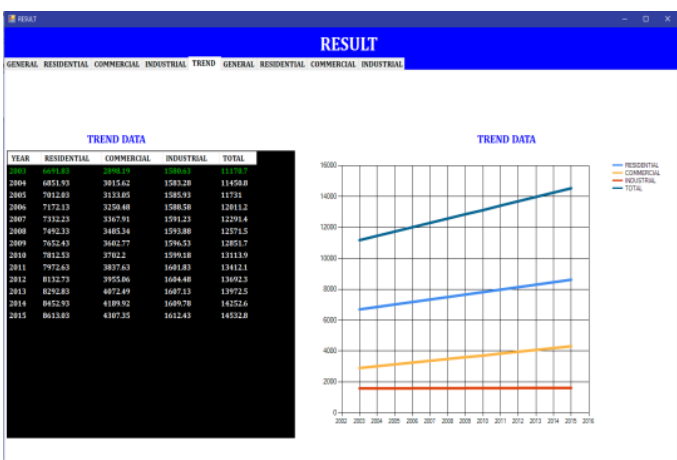

Fig. 7. Graph of Nigeria trend values from $2003-2015$

\section{CONCLUSION}

Recent blackouts have drawn public attention to the adequacy of transmission system and the need for its expansion. Transmission expansion planning becomes more difficult in the restructured electricity market environment because both economic and reliability assessments depend on system operation and many issues are intricately intertwined. In this thesis, we first propose an overall framework to clarify the models and solutions necessary for transmission expansion planning. We then review recent progress in economic aspect and engineering aspect of transmission investment and transmission planning.

Electricity supply in Nigeria is grossly inadequate, total installed capacity is far less than the demand and out of this installed capacity the available capacity is barely above half of the installed capacity. The per capita energy consumption is too low for meaningful economic and social development. In spite of this, Nigeria still has a constraint of supplying $70 \mathrm{MW}$ of energy to Niger Republic. Therefore, for the country to meet the Millennium Development Goals (MDGs), the Power Holding Company of Nigeria (PHCN), the Nigeria Electric Regulatory Commission (NERC) and the Federal Government should work towards generating or importing about $20,000 \mathrm{MW}$ of electricity which is about $300 \%$ of the present installed capacity.

Restructuring of the power system has received much attention around the world in the last two decades. Transmission expansion planning becomes more difficult in the restructured power system because of economic and system reliability both since system operation and many other issues are internally related. This research presents a proactive and realistic approach for transmission system expansion strategy planning in a systematic manner. The important basic issues to be taken care of while developing the transmission expansion planning is presented as fundamental care approach. The network expansion plan for effective management of generation capacity addition, reactive power, load growth, congestion, facilitating private sector projects and dealing uncertainties are dealt in detail. The factors explained in this paper, when taken into account assiduously, will aid in establishment of a model network.

\section{REFERENCES}

[1] A. Jager-Waldau, and H. Ossenbrink, "Progress of Electricity from Biomass, Wind and Photovoltaics in the European Union," Renewable and Sustainable Energy Review, vol. 8, no. 2, pp. 157-182, 2004.

[2] Energy Commission of Nigeria. Nigeria Energy Demand and Power Planning Study for the Period 2000-2030. Technical Report no. ECN/EPA/04/01 on Energy Masterplan Development, Abuja, 2004.

[3] Energy Commission of Nigeria. Renewable Energy Masterplan. Executive Report, Abuja, 2005.
[4] The Grid Code for the Nigerian Electricity Transmission System, Version 1. Grid Code, Abuja: Nigerian Electricity Regulatory Commission, 2010.

[5] N. Newman. "Power system investment planning using stochastic dual dynamic programming." PhD Thesis, University of Canterbury, New Zealand, 2008.

[6] G.C. Oliveria, A. P. Costa and S. Binato, "Large Scale Transmission Network Planning using Optimization and Heuristic Techniques," IEEE Trans, on Power System, vol. 10, no. 4, pp. 1828-1834, 1995.

[7] G. A. Orfanos, P. S. Georgilakis and N. D. Hatziargyriou, "Transmission Expansion Planning in Deregulated Electricity Markets for Increased Wind Power Penetration," European Market Conf., 2001.

[8] L. U. Miao, D. Z. Yang and R. S. T. Kuma, "A Framework for Transmission Planning in a Competitive Electricity Market," IEEE/ PES, Transmission and Distribution Conference Exhibition, Asia and Pacific Dalian China, 2005.

[9] M. O. Buygi, H. M. Shanechi, G. Balzer, and M. Shahidehpour, "Transmission Planning Approaches in Restructured Power Systems," IEEE Powertech, June 2006.

[10] A. H, Escobar, R. A. Gallego, and R. Romero, "Multistage and Coordinated Planning of the Expansion of Transmission Systems," IEEE Transactions on Power Systems, vol.19, no.2, pp. 735-744, 2004.

[11] F. Ibitoye and A. Adenikinju, "Future Demand for Electricity in Nigeria," Applied Energy, vol. 84, pp. 492-504, 2007.

[12] J. Ignacio, J. Perez-Arriga and L. Pedro, "Market vs Regulation, a Role for Indicative Energy Planning," 2008.

[13] M. R. Hesamzadeh, N. Hosseinzadeh and P. J. Wolfs, "Economic assessment of transmission expansion project in competitive market: an analytical review," $43^{\text {rd }}$ Universities Power Engineering Conference International, 1-4 Sept. 2008, Padova, Italy.

[14] E. Bueren, E. H. Klijn, and J. Koppenjan, "Dealing with Wicked Problems in Networks: Analyzing an Environmental Debate from a Network Perspective," Journal of Public Administration Research and Theory, vol. 13, no. 2, pp.193-212, 2003.

[15] A. M. Geoffrion, "Generalized Benders Decomposition," Journal of Optimization Theory Applications, vol. 10, pp. 237-260, 1972.

[16] A. J. Conejo, E. Castillo, and R. Minquez, Decomposition Techniques in Mathematical Programming: Engineering and Science Applications; Berlin Heidelberg: Springer, ISBN 3-540-27685-8, 2006.

[17] A. O. Ekwue, "Investigations of the transmission system expansion problem," International Journal of Electrical Power and Energy Systems, vol. 6, no. 3, pp. 139-142, 1984.

[18] A. M. Costa, "A survey on benders decomposition applied to fixedcharge network design problems," Computer and Operations Research, vol. 32, pp.1429-1450, 2005.

[19] H. M. Chebbo and M.R. Irving, "Application of Genetic Algorithms to Transmission Planning," $2^{\text {nd }}$ International Conference on Genetic Algorithms in Engineering Systems: Innovations and Applications, 2-4 Sept. 1997, Glasgow, UK.

[20] R. D. Dunlop, R Gutman, and P.P Marchenko. "Analytical Development of Loadability Characteristics for EHV and UHV Transmission Lines," IEEE Transactions on Power Apparatus and Systems, vol. PAS-98, No. 2, 1979.

[21] S. Cerisola, and A. Ramos, "Benders Decomposition for Mixed Integer Hydrothermal Problems by Lagrangean Relaxation," IEEE $14^{\text {th }}$ Power System Computation Conference, Seville, 2002.

[22] Y. P. Dusonchet and A. EL-Abiad, "Transmission Planning using Discrete Dynamic Optimization. IEEE Transactions on Power Apparatus and Systems, vol. PAS-92, no. 4, 1973

[23] L. L. Garver, "Transmission Network Estimation using Linear Programming," IEEE Transactions on Power Analysis System, vol. PAS-89, no. 7, pp.1688-1687, 1970

[24] L. G. Bayona, and I. T. Perez-Arriga, "A Heuristic Model for Long Term Transmission Expansion Planning," IEEE Transmissions Power System Planning, vol. 9, pp. 1886-1894, 1994.

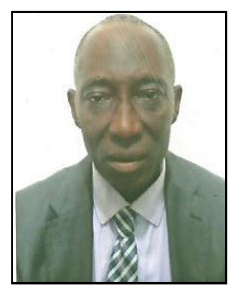

Christopher O. Ahiakwo received his M. Tech. and $\mathrm{PhD}$ in Electrical Engineering from Rivers State University of Science and Technology, Port Harcourt, Nigeria.

Professor Christopher Ahiakwo is a Professor of Electrical Engineering, with research interest in electrical power system and Renewable energy. He is a member of several professional bodies, including: Fellow, Nigerian Society of Engineers, Fellow, Nigerian Institution of Electrical Electronics Engineers, Member. Institute of Electrical Electronics Engineers, Council 
for the Regulation of Engineering in Nigeria, etc.

Professor Ahiakwo is currently the Dean, Faculty of Engineering, Rivers State University, Port Harcourt, Nigeria. He was a former Rector, Federal Polytechnic, Ekowe, Bayelsa State, Nigeria.

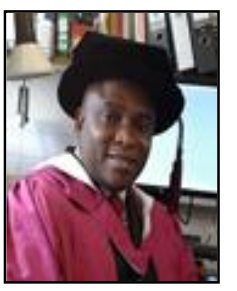

Sunny Orike received his B. Tech. in Compute Engineering from Rivers State University of Science and Technology, M.Sc. in Computing from Robert Gordon University, Aberdeen, United Kingdom and $\mathrm{Ph} . \mathrm{D}$ in Artificial Intelligence from Heriot-Watt University, Edinburgh, U.K.

$\mathrm{He}$ is an active member of several professional bodies, including Council for the Regulation of Engineering in Nigeria, Nigeria Institution of Electrical Electronic Engineers and International Association of Engineers. Dr. Sunny Orike is a Lecturer with the Department of Electrical \& Computer Engineering, Rivers State University, Port Harcourt, Nigeria.

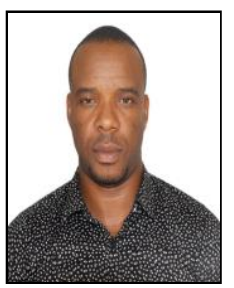

Ahuruezemma O. Obioma holds a B.Tech Degree in Electrical Engineering from Rivers State University of Science and Technology, PortHarcourt, Nigeria. He is currently undergoing his M.Tech in the Department of Electrical Engineering Rivers State University, Port-Harcourt, Nigeria.

Mr. Obioma has a certification on Cisco Certified

Network Professional (CCNP) and currently works with a Globacom Nigeria Limited as Transmission Engineer. 